\title{
Temperature-Sensitivity Analysis of 1360-nm Dilute-Nitride Quantum-Well Lasers
}

\author{
Jeng-Ya Yeh, Nelson Tansu, and Luke J. Mawst, Senior Member, IEEE
}

\begin{abstract}
The N-content of an InGaAsN quantum-well (QW) laser is found to dramatically affect the temperature sensitivity of the current injection efficiency $\left(\eta_{\mathrm{inj}}\right)$ and material gain parameter $\left(g_{\mathrm{oJ}}\right)$. The increased temperature sensitivity of $\eta_{\mathrm{inj}}$ and $g_{\mathrm{oJ}}$ of InGaAsN QW lasers with increasing $N$-content leads to a significant increase in their temperature sensitivity of threshold current and external differential quantum efficiency. Increasing the $\mathrm{N}$-content of the InGaAsN QW potentially results in a reduction of the heavy hole confinement, which may account for the increased temperature sensitivity of the current injection efficiency.
\end{abstract}

Index Terms-Current injection efficiency, InGaAsN, long wavelength quantum-well $(\mathrm{QW})$ laser, material gain, temperature sensitivity, thermionic carrier leakage.

\section{INTRODUCTION}

$\mathbf{S}$ EMICONDUCTOR lasers with emission wavelengths from 1300 to $1600 \mathrm{~nm}$ are crucial for the application of optical fiber communication systems. To achieve less temperature-sensitive GaAs-based quantum-well $(\mathrm{QW})$ lasers in this wavelength regime, InGaAsN was proposed as a promising candidate [1]. High performance devices have now been reported by many research groups [2]-[6] in the 1300-nm wavelength range. Because of the strong electron confinement in the InGaAsN QW structures, there is a potential for achieving less device temperature sensitivity compared to conventional InP-based lasers. Recent temperature analyses of InGaAsN diode lasers in the 1300-nm wavelength region indicate that the Auger recombination [7] and hole leakage [8] may play a significant role in the observed temperature sensitivity of the threshold current density and external differential quantum efficiency. To achieve emission wavelengths beyond $1300 \mathrm{~nm}$, higher $\mathrm{N}$-content InGaAsN active regions have been reported by various growth techniques such as molecular beam epitaxy [9], metal-organic chemical vapor deposition (MOCVD) [10], [11], and chemical beam epitaxy [12]. In addition to higher threshold current density and lower external differential quantum efficiency than those of 1300-nm-emitting lasers, the longer wavelength devices also exhibited severe temperature sensitivity of the laser characteristics. However, no study has yet focused on the strong temperature dependence of InGaAsN

Manuscript received September 11, 2003; revised November 13, 2003.

J.-Y. Yeh and L. J. Mawst are with the Reed Center for Photonics, Department of Electrical and Computer Engineering, University of Wisconsin-Madison, Madison, WI 53706-1691 USA (e-mail: jyeh@cae.wisc.edu).

$\mathrm{N}$. Tansu is with the Center for Optical Technologies, Department of Electrical and Computer Engineering, Lehigh University, Bethlehem, PA 18015 USA.

Digital Object Identifier 10.1109/LPT.2004.823715

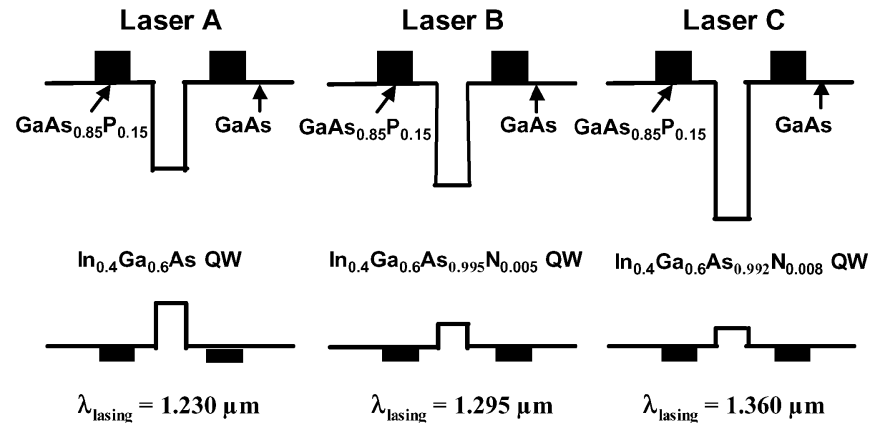

Fig. 1. Schematic band diagram of the $\operatorname{InGaAs}(\mathrm{N})$ QW laser structures with $\mathrm{N}$-content of $0 \%, 0.5 \%$, and $0.8 \%$ for $1230-\mathrm{nm} \mathrm{In}_{0.4} \mathrm{Ga}_{0.6} \mathrm{As}$ (Laser A), 1295-nm $\operatorname{In}_{0.4} \mathrm{Ga}_{0.6} \mathrm{As}_{0.995} \mathrm{~N}_{0.005}$ (Laser B), and 1360-nm $\mathrm{In}_{0.4} \mathrm{Ga}_{0.6} \mathrm{As}_{0.992} \mathrm{~N}_{0.008}$ (Laser $\mathrm{C}$ ) QW lasers, respectively.

QW lasers beyond $1300 \mathrm{~nm}$ and the underlying mechanism is still uncertain.

In this work, we present a temperature analysis of $\operatorname{InGaAs}(\mathrm{N})$ QW lasers over a wide emission wavelength range from 1230 to $1360 \mathrm{~nm}$ by simply adjusting the nitrogen composition in the QW. It was found that incorporation of higher nitrogen content significantly deteriorated the laser characteristics and temperature performance. Furthermore, we conclude that this behavior can be attributed to the highly temperature-sensitive current injection efficiency and material gain parameter for InGaAsN QW lasers with higher $\mathrm{N}$-content.

\section{Studied Laser Structures AND Performances}

The InGaAs QW and InGaAsN QW laser structures were grown by low-pressure MOCVD with trimethylgallium (TMGa), trimethylaluminum (TMAl), and trimethylindium (TMIn) as the precursors for group III materials, and $\mathrm{AsH}_{3}$, $\mathrm{PH}_{3}$, and U-dimethylhydrazine (U-DMHy) for the group $\mathrm{V}$ sources. In this study, we focused on three MOCVD-grown $\operatorname{InGaAs}(\mathrm{N}) \mathrm{QW}$ lasers with lasing wavelengths of $1.230 \mu \mathrm{m}$ (Laser A) [13], $1.295 \mu \mathrm{m}$ (Laser B) [3], and $1.360 \mu \mathrm{m}$ (Laser C) [11] for 2-mm-long devices, respectively, and the schematic band diagrams are shown in Fig. 1. A high In-content of $40 \%$ was utilized in the QW grown under a temperature of $530{ }^{\circ} \mathrm{C}$ for all three laser bases. The only distinction of these laser structures was the nitrogen composition $x$ of the $60-\AA$-thick $\mathrm{In}_{0.4} \mathrm{Ga}_{0.6} \mathrm{As}_{1-x} \mathrm{~N}_{x} \mathrm{QW}$, which was determined to be $0 \%$ and $0.5 \%$ for Lasers $\mathrm{A}$ and $\mathrm{B}$, calibrated by secondary ion-mass spectroscopy measurements, and $0.8 \%$ for Laser C, which was estimated by extrapolating the growth parameters. The calculated strain of the $\operatorname{InGaAs}(\mathrm{N}) \mathrm{QW}$ are $-2.79 \%,-2.69 \%$, and $-2.64 \%$, for Lasers A-C, respectively. The similar active layer strain values of these lasers should result in no signifi- 


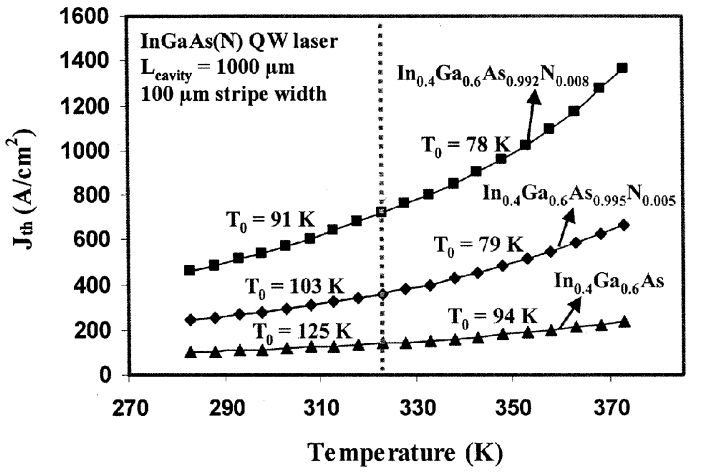

Fig. 2. $J_{\text {th }}$ as a function of temperature for Lasers A-C with $1000-\mu \mathrm{m}$ cavity length.

cant difference of the laser characteristics. The detailed laser structure was described in the previous published work [3], [11], [13]. The optical confinement factor $(\Gamma)$ of $1.7 \%$ was calculated for all three structures by using the transmission matrix method.

As-cleaved broad-area lasers were fabricated with a stripe width of $100 \mu \mathrm{m}$ and lasing characterization was conducted at a heat sink temperature range from $10{ }^{\circ} \mathrm{C}$ to $100{ }^{\circ} \mathrm{C}$ with a pulsewidth of $5 \mu$ s (1\% duty cycle). No heating was observed during the optical power versus injection current measurement under the experimental condition. The threshold current density $\left(J_{\text {th }}\right)$ was 110,266 , and 513 and external differential quantum efficiency $\left(\eta_{d}\right)$ was $48 \%, 46 \%$, and $43 \%$ at $20{ }^{\circ} \mathrm{C}$ for $1-\mathrm{mm}$ cavity length devices of Lasers A, B, and C, respectively. Fig. 2 shows the detailed temperature dependence of $J_{\text {th }}$ as well as the characteristic temperature $T_{0}\left\{1 / T_{0}=1 / J_{\mathrm{th}}\left(d J_{\mathrm{th}} / d T\right)\right\}$ at a temperature range of $10{ }^{\circ} \mathrm{C}-50{ }^{\circ} \mathrm{C}$ and $50{ }^{\circ} \mathrm{C}-100{ }^{\circ} \mathrm{C}$. The 1230-nm $\mathrm{In}_{0.4} \mathrm{Ga}_{0.6}$ As QW lasers (Laser A) have both the lowest $J_{\mathrm{th}}$ and the largest $\eta_{d}$ as well as higher $T_{0}$ and $T_{1}$ values compared with the 1295-nm $\operatorname{In}_{0.4} \mathrm{Ga}_{0.6} \mathrm{As}_{0.995} \mathrm{~N}_{0.005}$ (Laser B) and $1360-\mathrm{nm} \mathrm{In}_{0.4} \mathrm{Ga}_{0.6} \mathrm{As}_{0.992} \mathrm{~N}_{0.008}$ (Laser C) QW lasers. $T_{0}$ values from $20{ }^{\circ} \mathrm{C}$ to $60{ }^{\circ} \mathrm{C}$ were characterized to be $120 \mathrm{~K}$, $98 \mathrm{~K}$, and $88 \mathrm{~K}$ and $T_{1}$ are $631 \mathrm{~K}, 333 \mathrm{~K}$, and $227 \mathrm{~K}$ for Lasers A-C, respectively, indicating a trend of a reduction in $T_{0}$ and $T_{1}$ for the lasers with higher $\mathrm{N}$-content in QW. At $100{ }^{\circ} \mathrm{C}$, the InGaAs QW lasers exhibited a very low $J_{\mathrm{th}}$ of $237 \mathrm{~A} / \mathrm{cm}^{2}$ and high $\eta_{d}$ of $41 \%$. It is concluded that with an increasing N-content InGaAsN QW, the lasers show degraded lasing characteristics and, more importantly, significantly higher temperature sensitivity, although an extension of lasing wavelength can be achieved.

\section{TEMPERATURE ANALYSIS OF LASING CHARACTERISTICS}

The characteristic temperature coefficients $T_{0}$ and $T_{1}$ can be expressed as (1) and (2) by assuming that $J_{\mathrm{th}}$, transparent current density $\left(J_{\text {tr }}\right)$, and internal loss $\left(\alpha_{i}\right)$ exponentially increase with temperature while $\eta_{d}$, current injection efficiency $\left(\eta_{\mathrm{inj}}\right)$, and material gain parameter $\left(g_{\mathrm{oJ}}\right)$ exponentially decrease. The relations can be written as [8]

$$
\frac{1}{T_{0}(L)}=\frac{1}{T_{\mathrm{tr}}}+\frac{1}{T_{\eta_{\mathrm{inj}}}}+\frac{\alpha_{i}+\alpha_{m}(L)}{\Gamma \cdot g_{\mathrm{oJ}}} \cdot \frac{1}{T_{g_{\mathrm{oJ}}}}
$$

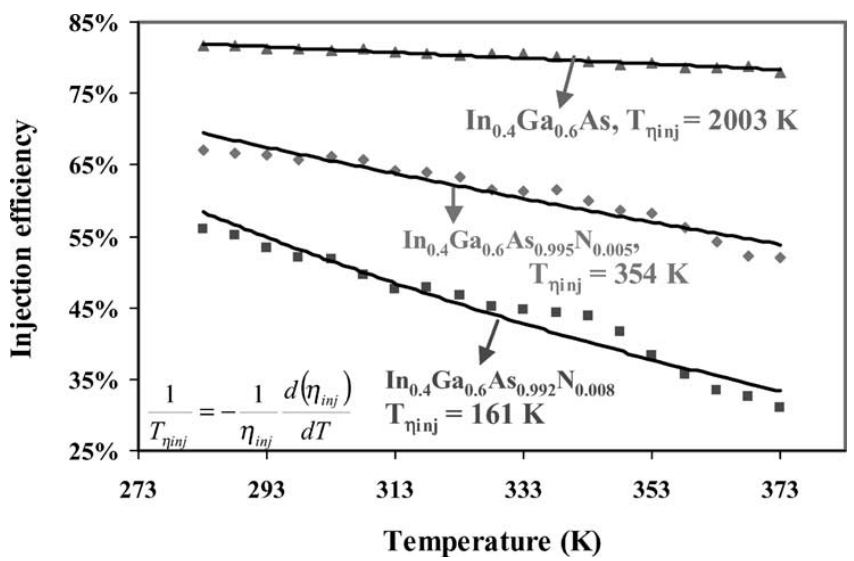

Fig. 3. Relation between current injection efficiency $\eta_{\text {inj }}$ and temperature for the three laser structures. A higher $T_{\eta_{\text {inj }}}$ was observed for the structure with less nitrogen in the QW.

$$
\begin{gathered}
+\frac{\alpha_{i}}{\Gamma \cdot g_{\mathrm{oJ}}} \cdot \frac{1}{T_{\alpha_{i}}} \\
\frac{1}{T_{1}(L)}=\frac{1}{T_{\eta_{\mathrm{inj}}}}+\frac{\alpha_{i}}{\alpha_{i}+\alpha_{m}(L)} \cdot \frac{1}{T_{\alpha_{i}}}
\end{gathered}
$$

where $T_{\mathrm{tr}}, T_{\eta_{\mathrm{inj}}}, T_{g_{\mathrm{oJ}}}$, and $T_{\alpha_{i}}$ are the characteristic temperatures of $J_{\mathrm{tr}}, \eta_{\mathrm{inj}}, g_{\mathrm{oJ}}$, and $\alpha_{i}$ and $\alpha_{m}(L)=(1 / L) \times \ln (1 / R)$ is the mirror loss as a function of cavity length, where $R$ is the facet reflectivity and $L$ is the cavity length. In order to distinguish the dominant mechanism for the poor temperature performance of the long wavelength 1360-nm InGaAsN QW lasers, temperature characteristics of $J_{\mathrm{tr}}, \eta_{\mathrm{inj}}$, and $g_{\mathrm{oJ}}$ were obtained from a series of temperature-dependent length studies. By deducing the slope and intercept of the $1 / \eta_{d}$ versus $L$ data line, one can calculate the laser intrinsic parameters of $\alpha_{i}$ and $\eta_{\text {inj }}$ [8].

The result of length studies for these three laser structures is shown in Fig. 3, where $\eta_{\text {inj }}$ is expressed as a function of heat sink temperature from $10^{\circ} \mathrm{C}$ to $100^{\circ} \mathrm{C}$. Current injection efficiency $\left(\eta_{\text {inj }}\right)$ values of $81 \%, 66 \%$, and $53 \%$ at room temperature and $T_{\eta_{\text {inj }}}$ of $2000 \mathrm{~K}, 354 \mathrm{~K}$, and $161 \mathrm{~K}$ were observed for the InGaAs(N) QW lasers with $0 \%, 0.5 \%$, and $0.8 \% \mathrm{~N}$-content, respectively. The strong temperature dependence of the injection efficiency indicates a much stronger carrier leakage process for the high $\mathrm{N}$-content InGaAsN QW lasers. At $100{ }^{\circ} \mathrm{C}$, the $\eta_{\text {inj }}$ of Laser $\mathrm{C}$ reduces to $31 \%$ while the $\eta_{\mathrm{inj}}$ of Laser A is still as high as $78 \%$. The second term in (2) represents the contribution from internal loss temperature sensitivity. Values of $T_{\alpha_{i}} \times\left(\alpha_{i}+\alpha_{m}\right) / \alpha_{i}$ were measured and calculated to be 640 , 1153 , and 2132 for Lasers A-C, respectively, and $T_{\alpha_{i}}$ values are $260 \mathrm{~K}, 360 \mathrm{~K}$, and $400 \mathrm{~K}$. According to (2), we can determine that the factor which limits $T_{1}$ for InGaAs QW laser is the internal loss (the second term) since $T_{\eta_{\text {inj }}}$ hardly affects $T_{1}$ due to its large value of $2000 \mathrm{~K}$. On the contrary, the dominant factor resulting in the highly temperature sensitive $\eta_{d}$ (a much lower $T_{1}$ ) of the 1295- and 1360-nm InGaAsN QW lasers is the current injection efficiency $\eta_{\text {inj }}(\mathrm{T})$ [the first term]. The observed poor $\eta_{\text {inj }}$ and $T_{\eta_{\text {inj }}}$ values could be presumably explained by a hole leakage mechanism in InGaAsN QW lasers [8], [14], [15] with a reducing valence band offset as nitrogen composition increases [16]. 


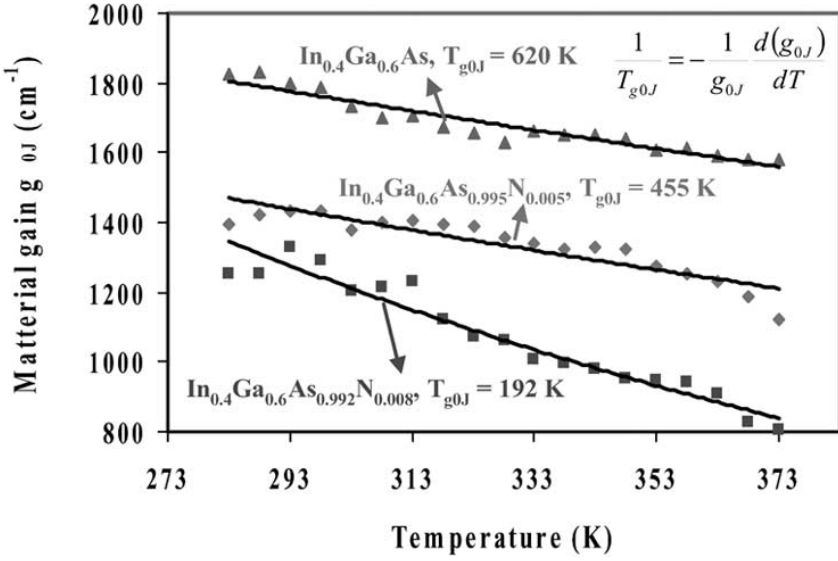

Fig. 4. Material gain parameter $g_{\mathrm{oJ}}$ versus temperature in a range of $10^{\circ} \mathrm{C}-100^{\circ} \mathrm{C}$. Higher $\mathrm{N}$-content results in both lower $g_{\mathrm{oJ}}$ and $T_{g_{\mathrm{O}} \mathrm{J}}$.

Unlike in (2), where $T_{\eta_{\text {inj }}}$ is the dominant factor, the more complicated dependence of (1) leads to difficulty in analyzing the dominant mechanism responsible for the degraded $T_{0}$ of InGaAsN QW lasers with increasing N-content. For the analysis of $T_{0}$, the first three terms in (1) are considered important and need to be carefully examined. In Fig. 4, the measured $g_{\mathrm{oJ}}$ values versus temperature are shown over a range of $10{ }^{\circ} \mathrm{C}-100{ }^{\circ} \mathrm{C}$. The $g_{\mathrm{OJ}}$ values at room temperature are measured to be 1800,1432 , and $1330 \mathrm{~cm}^{-1}$ and $T_{g_{\mathrm{OJ}}}$ values are $620 \mathrm{~K}, 456 \mathrm{~K}$, and $192 \mathrm{~K}$ for Lasers A-C, respectively. The 1360-nm InGaAsN QW lasers exhibit inferior gain characteristics compared with the other two structures and with such a low $T_{g_{\mathrm{oJ}}}$, the $g_{\mathrm{oJ}}$ value drops rapidly as temperature elevates and reaches a very low value of $800 \mathrm{~cm}^{-1}$ at $100{ }^{\circ} \mathrm{C}$. Possible mechanisms accounting for this behavior are Auger recombination, nitrogen-induced changes of the energy band structure, and temperature-sensitive carrier leakage processs below threshold. To achieve further insight, $g_{\mathrm{oJ}}$ and $T_{g_{\mathrm{oJ}}}$ values of $\mathrm{In}_{0.35} \mathrm{Ga}_{0.65} \mathrm{As}_{0.992} \mathrm{~N}_{0.008} \mathrm{QW}$ lasers are compared with $\mathrm{In}_{0.4} \mathrm{Ga}_{0.6} \mathrm{As}_{0.995} \mathrm{~N}_{0.005} \mathrm{QW}$ lasers in which the lasing wavelengths are designed to be $1.3 \mu \mathrm{m}$ for both cases. With identical bandgap energy, the contribution from Auger recombination are considered to be similar for these two laser structures. We find significantly lower values of $g_{\mathrm{oJ}}\left(1251 \mathrm{~cm}^{-1}\right.$ at $\left.20^{\circ} \mathrm{C}\right)$ and $T_{g_{\mathrm{oJ}}}$ (330 K from $10{ }^{\circ} \mathrm{C}-60{ }^{\circ} \mathrm{C}$ ) for the $\mathrm{In}_{0.35} \mathrm{Ga}_{0.65} \mathrm{As}_{0.992} \mathrm{~N}_{0.008}$ QW lasers, indicating that mechanisms other than Auger recombination play a significant role in the degradation of $g_{\mathrm{oJ}}$ and $T_{g_{\mathrm{oJ}}}$. From these data, it can be concluded that increasing $\mathrm{N}$-content in InGaAsN QW not only significantly reduces $\eta_{\text {inj }}$ and $T_{\eta_{\text {inj }}}$, but also seriously deteriorates $g_{\mathrm{oJ}}$ and $T_{g_{\mathrm{oJ}}}$. Based on this study, it is believed that the observed low $T_{0}$ and $T_{1}$ of InGaAsN QW lasers with increasing N-content can be explained by the combination of a more severe carrier leakage process and stronger temperature dependence of $g_{\mathrm{O}} \mathrm{J}$ [8].

\section{CONCLUSION}

This study demonstrates that the N-content in the InGaAsN QW dramatically affects the temperature sensitivity of $\eta_{\text {inj }}$ and
$g_{\mathrm{oJ}}$. The strong temperature dependence of $\eta_{\text {inj }}$ and $g_{\mathrm{oJ}}$ leads to low values of $T_{0}$ and $T_{1}$ for the InGaAsN QW lasers with higher N-content. The current injection efficiency of InGaAsN QW lasers with increasing $\mathrm{N}$-content exhibits increasing temperature sensitivity, which could result from a reduction of the heavy hole confinement. Suppression of thermionic carrier leakage by utilizing larger bandgap material as QW barriers may allow higher performance InGaAsN QW lasers with high $\mathrm{N}$-content for emission wavelength beyond $1360 \mathrm{~nm}$ or even up to $1550 \mathrm{~nm}$.

\section{REFERENCES}

[1] M. Kondow, K. Uomi, A. Niwa, T. Kitatani, S. Watahiki, and Y. Yazawa, "GaInNAs: A novel material for long-wavelength-range laser diodes with excellent high-temperature performance," Jpn. J. Appl. Lett., vol. 35, pp. 1273-1275, Feb. 1996.

[2] D. A. Livshits, A. Y. Egorov, and H. Riechert, "8 W continuous wave operation of InGaAsN lasers at $1.3 \mu \mathrm{m}$," Electron. Lett., vol. 36, pp. 1381-1382, Aug. 2000.

[3] N. Tansu, N. J. Kirsch, and L. J. Mawst, "Low-threshold-current-density 1300 nm dilute-nitride quantum lasers," Appl. Phys. Lett., vol. 81, no. 14, pp. 2523-2525, 2002.

[4] K. D. Choquette, J. F. Klem, A. J. Fischer, O. Blum, A. A. Allerman, I. J. Fritz, S. R. Kurtz, W. G. Breiland, R. Sieg, K. M. Geib, J. W. Scott, and R. L. Naone, "Room temperature continuous wave InGaAsN quantum well vertical-cavity lasers emitting at $1.3 \mu \mathrm{m}$," Electron. Lett., vol. 36, no. 16, pp. 1388-1390, 2000.

[5] M. Kawaguchi, T. Miyamoto, E. Gouardes, D. Schlenker, T. Kondo, F. Koyama, and K. Iga, "Lasing characteristics of low-threshold GaInNA's lasers grown by metalorganic chemical vapor deposition," Jpn. J. Appl. Phys., vol. 40, pp. L744-L746, July 2001.

[6] T. Takeuchi, Y.-L. Chang, M. Leary, A. Tandon, H.-C. Luan, D. P. Bour, S. W. Corzine, R. Twist, and M. R. Tan, " $1.3 \mu \mathrm{m}$ InGaAsN vertical cavity surface emitting lasers grown by MOCVD," Electron. Lett., vol. 38, no. 23, pp. 1438-1440, 2002.

[7] R. Fehse, S. Tomic, A. R. Adams, S. J. Sweeney, E. P. O'Reilly, A. Andreev, and H. Riechert, "A quantitative study of radiative, auger, and defect related recombination processes in 1.3- $\mu \mathrm{m}$ GaInNAs-based quantum-well lasers," IEEE J. Select. Topics Quantum Electron., vol. 8, pp. 801-810, July/Aug. 2002.

[8] N. Tansu and L. J. Mawst, "Temperature sensitivity of 1300-nm InGaAsN quantum-well lasers," IEEE Photon. Technol. Lett., vol. 14, pp. 1052-1054, Aug. 2002.

[9] W. Ha, V. Gambin, S. Bank, M. Wistey, H. Yuen, S. Kim, and J. S. Harris jr, "Long-wavelength GaInNAs(Sb) lasers on GaAs," IEEE J. Quantum Electron., vol. 38, pp. 1260-1267, Sept. 2002.

[10] F. Hohnsdorf, J. Koch, S. Leu, W. Stolz, B. Borchert, and M. Druminski, "Reduced threshold current densities of (GaIn)(NA's)/GaAs single quantum well lasers for emission wavelengths in the range 1.28-1.38 um," Electron. Lett., vol. 35, pp. 571-572, Apr. 1999.

[11] N. Tansu, J. Y. Yeh, and L. J. Mawst, "Low-threshold 1382-nm InGaAsN quantum-well lasers with metalorganic chemical vapor deposition," Appl. Phys. Lett., vol. , to be published.

[12] Y. Ikenaga, T. Miyamoto, S. Makino, T. Kageyama, M. Arai, F. Koyama, and K. Iga, "1.4 $\mu \mathrm{m}$ GaInNAs/GaAs quantum well laser grown by chemical beam epitaxy," Jpn. J. Appl. Phys., vol. 41, pp. 664-665, Feb. 2002.

[13] N. Tansu, J. Y. Yeh, and L. J. Mawst, "Extremely low threshold-current-density ingaas quantum-well lasers with emission wavelength of 1215-1233 nm," Appl. Phys. Lett., vol. 82, pp. 4038-4040, June 2003.

[14] N. Tansu and L. J. Mawst, "The role of hole leakage in 1300-nm InGaAsN quantum-well lasers," Appl. Phys. Lett., vol. 82, pp. 1500-1502, Mar. 2003.

[15] N. Tansu, J. Y. Yeh, and L. J. Mawst, "Experimental evidence of carrier leakage in InGaAsN quantum well lasers," Appl. Phys. Lett., vol. 83, no. 11, pp. 2112-2114, Sept. 2003.

[16] M. Hetterich, M. D. Dawson, A. Y. Egorov, D. Bernklau, and H. Riechert, "Electronic states and band alignment in GaInNAs/GaAs quantum-well structures with low nitrogen content," Appl. Phys. Lett., vol. 76, pp. 1030-1032, Feb. 2000. 